Check for updates

Cite this: Chem. Commun., 2020, 56,5429

Received 27th March 2020

Accepted 6th April 2020

DOI: $10.1039 / \mathrm{d} 0 \mathrm{cc} 02253 \mathrm{e}$

rsc.li/chemcomm

\section{Sulfoxide synthesis from sulfinate esters under Pummerer-like conditions $\dagger$}

\author{
Akihiro Kobayashi, Tsubasa Matsuzawa, Takamitsu Hosoya (DD and \\ Suguru Yoshida (D) *
}

A facile synthetic method for the preparation of allyl sulfoxides by $S$-allylation of sulfinate esters proceeds through sulfonium intermediates without [3,3]-sigmatropic rearrangement and further Pummerer-type reactions of the resulting allyl sulfoxides. On the basis of the plausible reaction mechanism involving sulfonium salt intermediates, $S$-alkynylation and $S$-arylation were also accomplished.

Organosulfur compounds have gained attention in a broad range of research fields such as pharmaceutical sciences, agrochemistry, and materials science. ${ }^{1,2}$ The recent remarkable successes of synthetic chemistry using sulfoxides have enhanced the accessibility of highly functionalized compounds by virtue of the significant transformability of sulfoxides. $^{3-8}$ For example, the preparations of diverse compounds 2-5 were achieved by a variety of transformations of allyl aryl sulfoxides 1 through $\mathrm{C}-\mathrm{S}$ bond cleavage (Fig. 1A). ${ }^{6,7,8 h, j}$ In particular, multisubstituted aromatic sulfides $\mathbf{4}$ and $\mathbf{5}$ were synthesized from sulfoxides $\mathbf{1}$ by a reaction with aryne intermediate $\mathbf{I}$ in the presence of electrophiles and the $[3,3]$-sigmatropic rearrangement of allyl sulfonium intermediate II, respectively. ${ }^{6,7}$ Similar interrupted Pummerer reactions of sulfoxides $\mathbf{6}$ and $\mathbf{8}$ with trifluoromethanesulfonic anhydride $\left(\mathrm{Tf}_{2} \mathrm{O}\right)$ in the presence of allyltrimethylsilane were also accomplished through the [3,3]-sigmatropic rearrangement, showing the notable reactivity of allyl sulfonium intermediates III and IV (Fig. 1B and C). ${ }^{4 b, d, e, n}$ Herein, we describe an efficient synthesis of various allyl sulfoxides by allylation of sulfinate esters ${ }^{9}$ using allyltrimethylsilane under the Pummerer-like conditions ${ }^{4}$ through sulfonium intermediate $\mathbf{V}$ having a methoxy group, enabling to avoid the [3,3]-sigmatropic rearrangement and further Pummerertype reactions of the resulting allyl sulfoxides (Fig. 1D).

Sulfinate esters hitherto have served in the sulfoxide synthesis with Grignard reagents. ${ }^{9 a}$ Recently, Lewis acid-mediated

Laboratory of Chemical Bioscience, Institute of Biomaterials and Bioengineering, Tokyo Medical and Dental University (TMDU), 2-3-10 Kanda-Surugadai,

Chiyoda-ku, Tokyo 101-0062, Japan. E-mail: s-yoshida.cb@tmd.ac.jp

$\dagger$ Electronic supplementary information (ESI) available: Experimental procedures, characterization for new compounds including NMR spectra. See DOI: 10.1039/ docc02253e

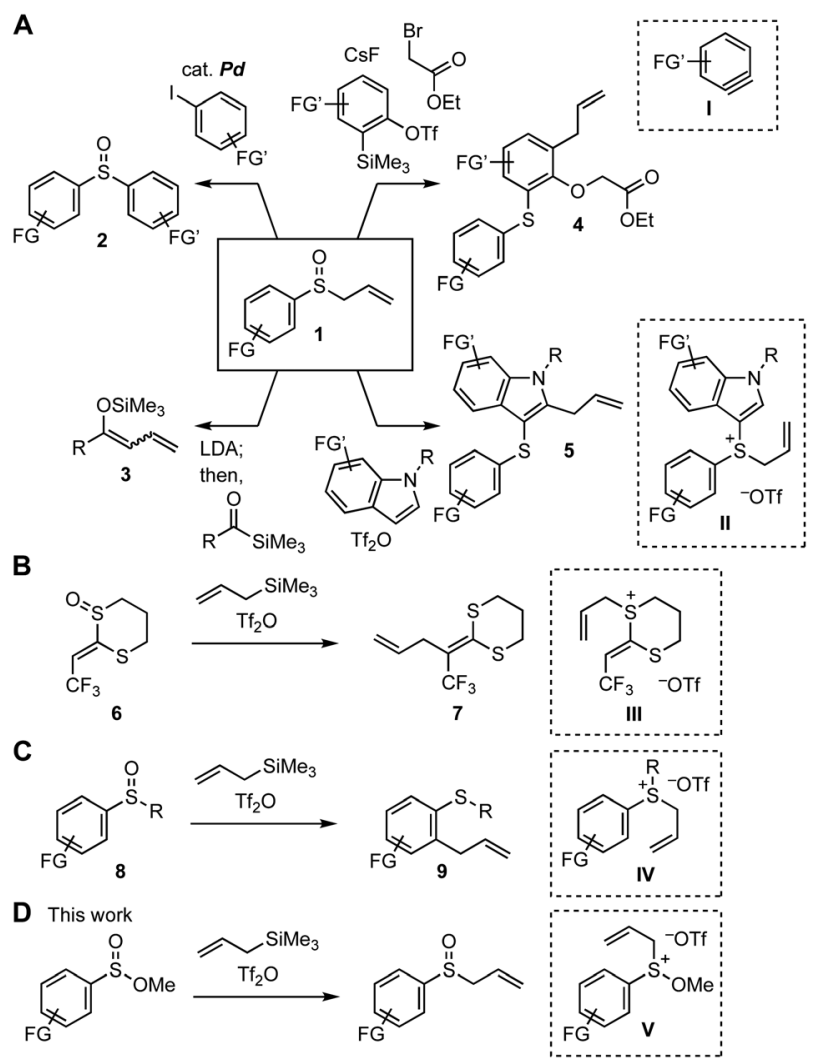

Fig. 1 Transformations through the Pummerer-type activation of sulfoxides and sulfinate esters. (A) Versatile transformations using allyl sulfoxides 1. (B) Interrupted Pummerer reaction of ketenedithioacetal monoxide $\mathbf{6}$. (C) Interrupted Pummerer reaction of aromatic sulfoxide 8 . (D) This work.

Friedel-Crafts-type sulfinylation of electron-rich arenes using sulfinate esters was developed. ${ }^{9 b}$ Taking the sulfinate ester chemistry into account, we envisioned that the Pummerer-type activation of sulfinate esters $\mathbf{1 0}$ in the presence of allylsilanes $\mathbf{1 1}$ and stability of methoxy sulfonium intermediates ${ }^{10}$ would allow for the facile synthesis of allyl sulfoxides 12, considering that the hydrolysis of methoxy sulfonium intermediates $\mathbf{V}^{\prime}$ can 
afford sulfoxides (Fig. 2A). As a result of screening the reaction conditions, we found that treatment of methyl benzenesulfinate (10a) with $\mathrm{Tf}_{2} \mathrm{O}$ in the presence of allyltrimethylsilane (11a) followed by addition of aqueous sodium bicarbonate provided allyl phenyl sulfoxide (12a) in high yield (Fig. 2A and 2B). Examinations using a variety of acid anhydrides or Lewis acids showed the remarkable reactivity of $\mathrm{Tf}_{2} \mathrm{O}$ in the $S$-allylation of sulfinate ester 10a. ${ }^{11,12} \mathrm{~A}$ wide range of allyl sulfoxides $\mathbf{1 2 b}-\mathbf{1 2 j}$ were prepared by the $S$-allylation under the Pummerer-like conditions, where $C$-allylation products through the [3,3]-sigmatropic rearrangement were not obtained. Indeed, not only electron-rich aromatic sulfinate esters bearing methyl and methoxy groups but also electron-deficient substrates with chloro and nitro groups were efficiently allylated to furnish sulfoxides 12b-12e. Sulfoxides 12f and $\mathbf{1 2} \mathrm{g}$ were obtained uneventfully by the reactions of bulky 2-bromo- and 2,6-dimethyl-substituted benzenesulfinate esters. Furthermore, $S$-allylations of 2-naphthyl-, benzyl-, and $n$-pentylsubstituted sulfinate esters also took place smoothly to provide sulfoxides 12h-12j.

Various functionalized allylsilanes $\mathbf{1 1}$ participated in the $S$ allylation of sulfinate ester 10a (Fig. 2A and C). ${ }^{13}$ Sulfoxides 12k and $\mathbf{1 2 l}$ were efficiently synthesized by 2-methyl- and 2-phenylallylation, respectively. It is worth noting that the $\mathrm{C}-\mathrm{S}$ bond formation enabled to prepare allyl chloride 12m, allyl acetate

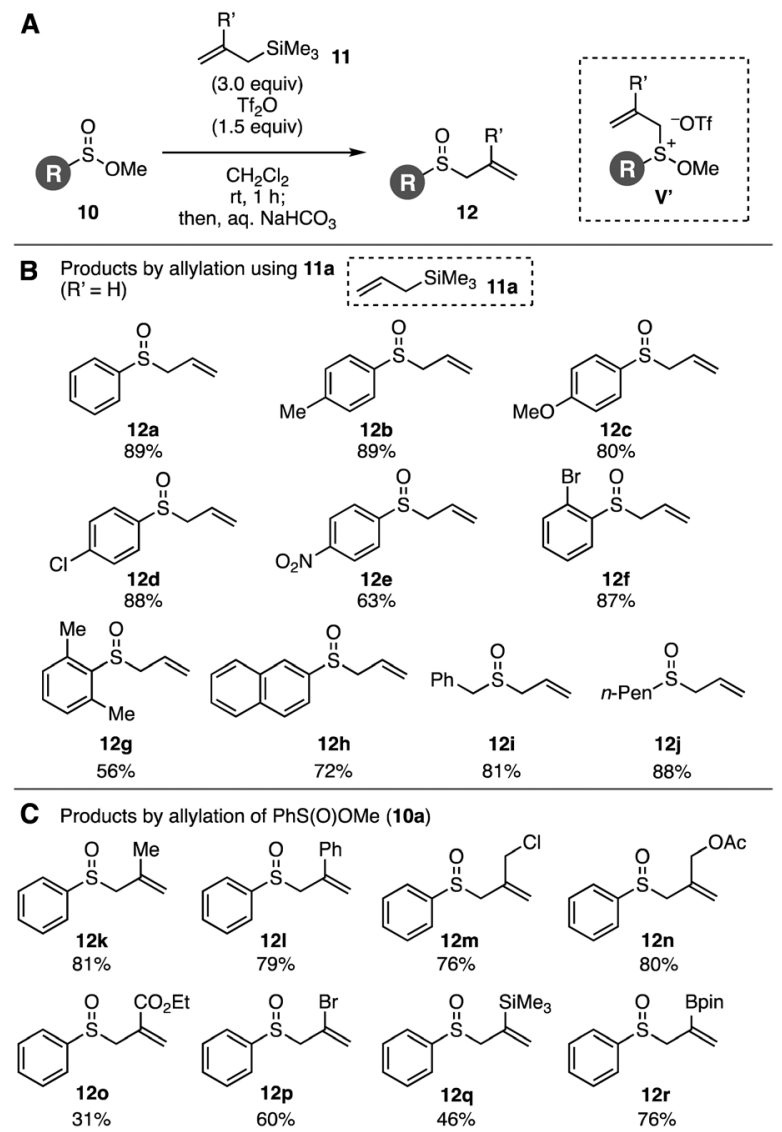

Fig. 2 Allyl sulfoxide synthesis from sulfinate esters $\mathbf{1 0}$ and allylsilanes $\mathbf{1 1}$ (A) General scheme. (B) Results using various sulfinate esters 10 with 11a. (C) Results using allylsilanes 11 with $10 a$. 12n, ester 12o, and bromoalkene 12p leaving highly electrophilic functional groups untouched, while it is not easy to synthesize sulfoxides having electrophilic moieties by the conventional allyl sulfoxide synthesis via allylation of thiols and subsequent oxidation. Moreover, transformable sulfoxides 12q and 12r possessing a silyl and boryl groups were obtained in moderate to good yields without damaging these reactive functional groups.

To gain insight into the reaction mechanism of the $S$-allylation of sulfinate esters under the Pummerer-like conditions, we then examined control experiments (Fig. 3). Firstly, the reaction using $\left[{ }^{18} \mathrm{O}\right] \mathrm{H}_{2} \mathrm{O}$ in the hydrolysis using aqueous sodium bicarbonate was conducted to clarify the origin of the oxygen atom of sulfoxide 12a (Fig. 3A). The result showed that ${ }^{18} \mathrm{O}$-incorporated $\mathbf{1 2 a}^{\prime}$ was obtained selectively, indicating that the sulfoxide oxygen was derived from water in the hydrolysis. We then attempted to isolate sulfonium intermediate $\mathbf{1 3}$ (Fig. 3B). As a result, after sulfinate ester 10a was treated with $\mathrm{Tf}_{2} \mathrm{O}$ in the presence of allylsilane 11a, an addition of solid sodium bicarbonate, filtration of the resulting mixture, removal of the solvent of the filtrate, and washing with diethyl ether afforded sulfonium salt 13 quantitatively. Hydrolysis of sulfonium salt 13 with aqueous sodium bicarbonate underwent uneventfully to give sulfoxide 12a. In addition, reduction of sulfonium salt 13 with sodium borohydride successfully provided allyl phenyl sulfide (14) in good yield. ${ }^{10 c}$ On the basis of these results, we proposed a reaction mechanism of the $S$-allylation (Fig. 3C). The Pummerer-type activation of sulfinate ester by virtue of the remarkable reactivity of $\mathrm{Tf}_{2} \mathrm{O},{ }^{14}$ and following $S$-allylation of the resulting sulfonium intermediate VI would furnish sulfonium intermediate 13 along with trimethylsilyl triflate. Then, hydrolysis of sulfonium salt $\mathbf{1 3}$ with aqueous sodium bicarbonate involving the nucleophilic attack of external water to the sulfur atom leads

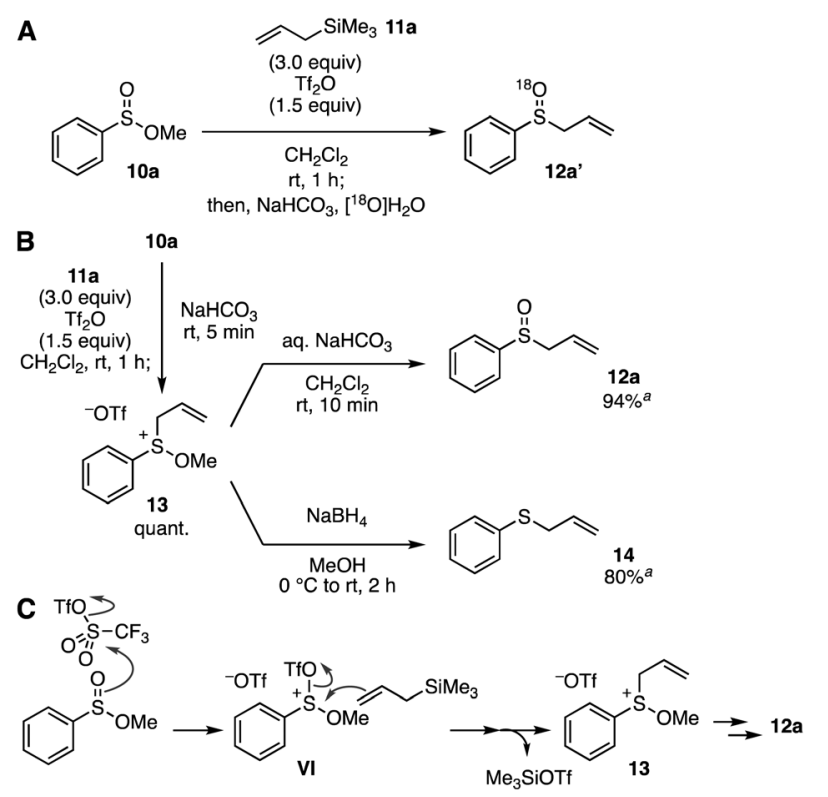

Fig. 3 Control experiments. (A) Reaction using $\left[{ }^{18} \mathrm{O}\right] \mathrm{H}_{2} \mathrm{O}$. (B) Isolation of sulfonium salt 13 , hydrolysis of 13 , and reduction of 13 . (C) Plausible reaction mechanism. ${ }^{a}{ }^{1} \mathrm{H}$ NMR yield. 


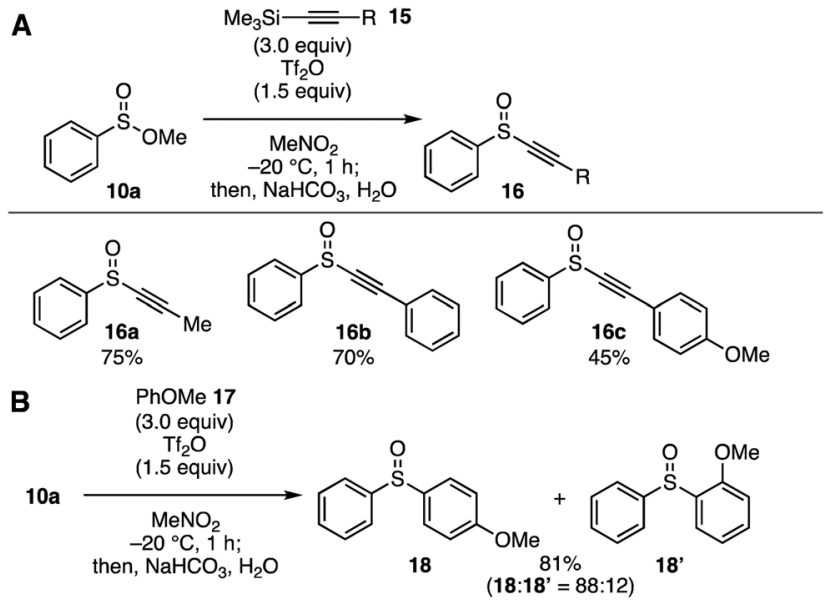

Fig. 4 Alkynylation and arylation of sulfinate ester 10a. (A) Alkynylation with alkynylsilanes 15. (B) Arylation with anisole (17).

to sulfoxide 12a. Although the role of methoxy group is still unclear, the stability of sulfonium salt $\mathbf{1 3}$ would achieve the sulfoxide synthesis without $[3,3]$-sigmatropic rearrangement or the Pummerer-type reactions of allyl sulfoxide 12a and further Pummerer-type reactions of the resulting allyl sulfoxides. ${ }^{15}$

Our attention then directed toward novel transformations through the cationic intermediates generated by the Pummerertype activation of sulfinate esters with $\mathrm{Tf}_{2} \mathrm{O}$ (Fig. 4). In this context, we have developed a facile synthetic method of alkynyl sulfoxides 16 using alkynyl silanes 15 (Fig. 4A). Indeed, treatment of sulfinate ester 10a dissolved in nitromethane with $\operatorname{Tf}_{2} \mathrm{O}$ in the presence of ethynylsilanes 15 at $-20{ }^{\circ} \mathrm{C}$ furnished alkynyl sulfoxides 16 in moderate to high yields. This novel transformation enabled the preparation of alkynyl sulfoxides 16a-16c having a methyl, phenyl, and 4-anisyl group. Since alkynyl sulfoxides serve in a variety of reactions including carbometallation, [2+2] cycloaddition, and cyclopropanation, the alkynyl sulfoxide synthesis developed in this study would allow for the preparation of a range of organosulfur compounds. ${ }^{4 k, 16}$ In addition, Friedel-Crafts-type arylation of sulfinate ester 10a also took place smoothly to afford a regioisomeric mixture of diaryl sulfoxides 18 and $\mathbf{1 8}^{\prime}$ in good yield (Fig. 4B). ${ }^{9 b}$

Wide transformability of allyl aryl sulfoxides synthesized from sulfinate esters was showcased by the syntheses of multisubstituted aromatic compounds (Fig. 5). Modifying the conditions for the trifunctionalization of aryne intermediates reported by $\mathrm{Li}$ and coworkers ${ }^{6}$ (Fig. 1A, 1 to 4), we found that 2,3,6-trisubstituted phenol 20a was obtained in moderate yield with avoiding further arylation between phenol 20a and 3-methoxybenzyne when the aryne trifunctionalization was performed in hot 1,4-dioxane ${ }^{5 d}$ in the absence of electrophiles such as ethyl bromoacetate (Fig. 5A). Iodine-mediated cyclization of the resulting phenol 20a and subsequent elimination with a base successfully furnished benzofuran $21 .{ }^{17}$ Methallylation of sulfinate ester $\mathbf{1 0 d}$ followed by the aryne trifunctionalization led to the synthesis of highly functionalized phenol 20b (Fig. 5B). Furthermore, tetrasubstituted indole $\mathbf{2 3}$ was prepared through 2-bromoallylation

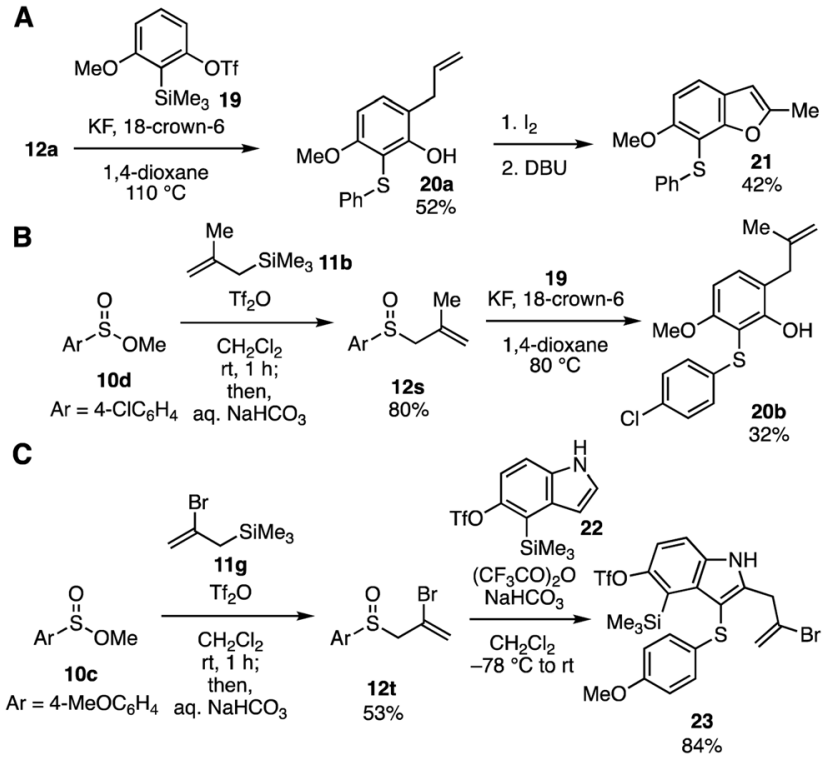

Fig. 5 Transformations of allyl sulfoxides. (A) Benzofuran synthesis. (B) Trisubstituted phenol synthesis. (C) Multisubstituted indole synthesis.

of sulfinate ester 10c and following 2,3-difunctionalization of indole 22 according to the reports by Procter and coworkers ${ }^{7}$ (Fig. 5C). Functionalized allyl aryl sulfoxide 12t and indole 22 bearing $o$-silylaryl triflate moiety ${ }^{18}$ for the aryne generation participated in the 2,3-disubstituted indole synthesis leaving the reactive functional groups intact. Thus, a wide variety of indoles would be synthesized by $S$-allylation of sulfinate esters, 2,3-difunctionalization of indoles, and further transformations through indolyne intermediates with a number of arynophiles. ${ }^{18,19}$

In summary, we have developed a facile synthetic method of allyl sulfoxides by $S$-allylation of sulfinate esters through sulfonium intermediates without [3,3]-sigmatropic rearrangement and further Pummerer-type reactions of the resulting allyl sulfoxides. On the basis of the plausible reaction mechanism, $S$-alkynylation and $S$-arylation were also accomplished. Further studies to expand the scope of these transformations using sulfinate esters under the Pummerer-like conditions, chiral sulfoxide synthesis, and the applications to the synthesis of bioactive compounds are now in progress.

The authors thank Dr Yuki Sakata at Tokyo Medical and Dental University for HRMS analyses. This work was supported by JSPS KAKENHI Grant Numbers JP19K05451 (C; S.Y.), JP18H02104 (B; T.H.), JP18H04386 (Middle Molecular Strategy; T.H.), and 19J14128 (JSPS Research Fellow; T.M.); the Naito Foundation (S.Y.); the Japan Agency for Medical Research and Development (AMED) under Grant Number JP19am0101098 (Platform Project for Supporting Drug Discovery and Life Science Research, BINDS); and the Cooperative Research Project of Research Center for Biomedical Engineering.

\section{Conflicts of interest}

There are no conflicts to declare. 


\section{Notes and references}

1 For selected reviews of bioactive sulfur-containing compounds, see: (a) K. Pluta, B. Morak-Młodawska and M. Jeleń, Eur. J. Med. Chem., 2011, 46, 3179; (b) E. A. Ilardi, E. Vitaku and J. T. Njardarson, J. Med. Chem., 2014, 57, 2832.

2 For selected reviews of sulfur-containing compounds in materials science, see: (a) A. S. Rahate, K. R. Nemade and S. A. Waghuley, Rev. Chem. Eng., 2013, 29, 471; (b) S. Dadashi-Silab, C. Aydogan and Y. Yagci, Polym. Chem., 2015, 6, 6595.

3 (a) S. K. Bur and A. Padwa, Chem. Rev., 2004, 104, 2401; (b) K. S. Feldman, Tetrahedron, 2006, 62, 5003; (c) S. Akai and Y. Kita,, Top. Curr. Chem., 2007, 274, 35; (d) L. H. S. Smith, S. C. Coote, H. F. Sneddon and D. J. Procter, Angew. Chem., Int. Ed., 2010, 49, 5832; (e) X. Huang, S. Klimczyk and N. Maulide, Synthesis, 2012, 175; $(f)$ A. Shafir, Tetrahedron Lett., 2016, 57, 2673; $(g)$ A. P. Pulis and D. J. Procter, Angew. Chem., Int. Ed., 2016, 55, 9842; (h) H. Yorimitsu, Chem. Rec., 2017, 17, 1156; (i) T. Yanagi, K. Nogi and H. Yorimitsu, Tetrahedron Lett., 2018, 59, 2951; ( $j$ ) D. Kaiser, I. Klose, R. Oost, J. Neuhaus and N. Maulide, Chem. Rev., 2019, 119, 8701; (k) L. Zhang, M. Hu and B. Peng, Synlett, 2019, 2203.

4 For selected examples, (a) S. Akai, N. Kawashita, H. Satoh, Y. Wada, K. Kakiguchi, I. Kuriwaki and Y. Kita, Org. Lett., 2004, 6, 3793; (b) S. Yoshida, H. Yorimitsu and K. Oshima, Org. Lett., 2009, 11, 2185; (c) X. Huang and N. Maulide, J. Am. Chem. Soc., 2011, 133, 8510; (d) A. J. Eberhart, J. Cicoira, E. Imbriglio and D. J. Procter, Org. Lett., 2011, 13, 5882; (e) A. J. Eberhart, C. Cicoira and D. J. Procter, Org. Lett., 2013, 15, 3994; $(f)$ M. Tayu, K. Higuchi, T. Ishizaki and T. Kawasaki, Org. Lett., 2014, 16, 361; $(g)$ G. Hu, J. Xu and P. Li, Org. Lett., 2014, 16, 6036; (h) L. Hu, Q. Gui, X. Chen, Z. Tan and G. Zhu, J. Org. Chem., 2016, 81, 4861; (i) D. Chen, Q. Feng, Y. Yang, X.-M. Cai, F. Wang and S. Huang, Chem. Sci., 2017, 8, 1601; (j) L. Shang, Y. Chang, F. Luo, J.-N. He, X. Huang, L. Zhang, L. Kong, K. Li and B. Peng, J. Am. Chem. Soc., 2017, 139, 4211; (k) D. Kaldre, I. Klose and N. Maulide, Science, 2018, 361, 664; $(l)$ L. Zhang, J.-N. He, Y. Liang, M. Hu, L. Shang, X. Huang, L. Kong, Z.-X. Wang and B. Peng, Angew. Chem., Int. Ed., 2019, 58, 5316; (m) K. Okamoto, M. Hori, T. Yanagi, K. Murakami, K. Nogi and H. Yorimitsu, Angew. Chem., Int. Ed., 2019, 58, 7813; (n) J. Yan, A. P. Pulis, G. J. P. Perry and D. J. Procter, Angew. Chem., Int. Ed., 2019, 58, 15675; (o) X. Meng, D. Chen, X. Cao, J. Luo, F. Wang and S. Huang, Chem. Commun., 2019, 55, 12495; (p) J. Li, Y. Chen, R. Zhong, Y. Zhang, J. Yang, H. Ding and Z. Wang, Org. Lett., 2020, 22, 1164; (q) Z. He, G. J. Perry and D. J. Procter, Chem. Sci., 2020, 11, 2001; (r) X. Huang, Y. Zhang, W. Liang, Q. Zhang, Y. Zhan, L. Kong and B. Peng, Chem. Sci., 2020, 11, 3048.

5 For our previous reports on sulfoxides chemistry, see: (a) S. Yoshida, K. Uchida and T. Hosoya, Chem. Lett., 2014, 43, 116; (b) S. Yoshida, K. Uchida and T. Hosoya, Chem. Lett., 2015, 44, 691; (c) S. Yoshida, F. Karaki, K. Uchida and T. Hosoya, Chem. Commun., 2015, 51, 8745; (d) T. Matsuzawa, K. Uchida, S. Yoshida and T. Hosoya, Org. Lett., 2017, 19, 5521; (e) Y. Nakamura, Y. Miyata, K. Uchida, S. Yoshida and T. Hosoya, Org. Lett., 2019, 21, 5252.

6 Y. Li, D. Qiu, R. Gu, J. Wang, J. Shi and Y. Li, J. Am. Chem. Soc., 2016, 138, 10814.

7 M. Siaučiulis, S. Sapmaz, A. P. Pulis and D. J. Procter, Chem. Sci., 2018, 9, 754.

8 (a) R. Hunter and C. D. Simon, Tetrahedron Lett., 1986, 27, 1385; (b) Y. Kita, O. Tamura, F. Itoh, H. Yasuda, T. Miki and Y. Tamura, Chem. Pharm. Bull., 1987, 35, 562; (c) D. H. Hua, M. J. Coulter and I. Badejo, Tetrahedron Lett., 1987, 28, 5465; (d) M. R. Binns, R. K. Haynes, A. G. Katsifis, P. A. Schober and S. C. Vonwiller, J. Am. Chem. Soc., 1988, 110, 5411; (e) R. Hunter and C. D. Simon, Tetrahedron Lett., 1988, 29, 2257; $(f)$ E. Alonso, D. Guijarro and M. Yus,
Tetrahedron, 1995, 51, 2699; $(g)$ W. A. Loughlin and M. A. McCleary, Synthesis, 2005, 761; $(h)$ E. Bernoud, G. Le Duc, X. Bantreil, G. Prestat, D. Madec and G. Poli, Org. Lett., 2010, 12, 320; (i) S. Fustero, S. Catalán, M. Sánchez-Roselló, A. Simón-Fuentes and C. del Pozo, Org. Lett., 2010, 12, 3484; $(j)$ M. Honda, T. Nakajima, M. Okada, K. Yamaguchi, M. Suda, K.-K. Kunimoto and M. Segi, Tetrahedron Lett., 2011, 52, 3740; (k) Z. Huang and J. Xu, RSC Adv., 2013, 3, 15114; (l) D. Qiu, J. Shi, Q. Guo, Q. Xu, B. Li and Y. Li, J. Am. Chem. Soc., 2018, 140, 13214.

9 For the sulfoxide synthesis with Grignard reagents, see: $(a)$ H. Gilman, J. Robinson and N. J. Beaber, J. Am. Chem. Soc., 1926, 48, 2715; For recent transformations of sulfinate esters, see: $(b)$ F. Yuste, A. H. Linares, V. M. Mastranzo, B. Ortiz, R. Sánchez-Obregón, A. Fraile, J. Luis and G. Ruano, J. Org. Chem., 2011, 76, 4635; (c) J. A. Lujan-Montelongo, A. O. Estevez and F. F. Fleming, Eur. J. Org. Chem., 2015, 1602; (d) N.-L. T. Nguyen, H.-T. Vo, F. Duus and T. X. T. Luu, Molecules, 2017, 22, 1458; (e) A. Mohd, T. Anitha, K. R. Reddy, J. Wencel-Delord and F. Colobert, Eur. J. Org. Chem., 2019, 7836; $(f)$ G.-J. Li, Y.-L. Pan, Y.-L. Liu, H.-F. Xu and J.-Z. Chen, Tetrahedron Lett., 2019, 60, 151260; $(g)$ L. Chen, J. Zhang, Y. Wei, Z. Yang, P. Liu, J. Zhang and B. Dai, Tetrahedron, 2019, 75, 130664.

10 (a) C. R. Johnson and W. G. Phillips, Tetrahedron Lett., 1965, 6, 2101; (b) C. R. Johnson and W. G. Phillips, J. Org. Chem., 1967, 32, 1926; (c) C. R. Johnson and W. G. Phillips, J. Org. Chem., 1967, 32, 3233. 11 See the $\mathrm{ESI} \dagger$ for the details.

12 The reaction at $80{ }^{\circ} \mathrm{C}$ in a sealed tube also provided sulfoxide 12a, where [3,3]-sigmatropic rearrangement did not proceed.

13 The reaction using a $\gamma$-phenyl-substituted allylsilane afforded a complex mixture of products.

14 For recent examples, see: (a) Y. Unoh, K. Hirano and M. Miura, J. Am. Chem. Soc., 2017, 139, 6106; (b) H. Huang, J. Ash and J. Y. Kang, Org. Lett., 2018, 20, 4938; (c) C. R. Goncąlves, M. Lemmerer, C. J. Teskey, P. Adler, D. Kaiser, B. Maryasin, L. Gonzalez and N. Maulide, J. Am. Chem. Soc., 2019, 141, 18437; (d) J. Wang, Y.-J. Deng, X.-X. Yan, Y.-J. Liu, C.-P. Ge, Y. Yan, S. Chao and P.-X. Zhou, Org. Chem. Front., 2020, 7, 715.

15 Although detailed studies involving the theoretical calculation should be performed, the resonance effect of the methoxy group might prevent the $[3,3]$-sigmatropic rearrangement leading to the sulfenate.

16 (a) J. P. Marino, M. B. Rubio, G. Cao and A. de Dios, J. Am. Chem. Soc., 2002, 124, 13398; (b) G. Sklute, D. Amsallem, A. Shabli, J. P. Varghese and I. Marek, J. Am. Chem. Soc., 2003, 125, 11776; (c) N. Maezaki, S. Yagi, R. Yoshigami, J. Maeda, T. Suzuki, S. Ohsawa, K. Tsukamoto and T. Tanaka, J. Org. Chem., 2003, 68, 5550; (d) Q. Xu and X. Huang, Tetrahedron Lett., 2004, 45, 5657; (e) G. Sklute and I. Marek, J. Am. Chem. Soc., 2006, 128, 4642; $(f)$ F. Sandrinelli, C. Boudou, C. Caupène, M.-T. Averbuch-Pouchot, S. Perrio and P. Metzner, Synlett, 2006, 3289; (g) G. Zhang and L. Zhang, J. Am. Chem. Soc., 2008, 130, 12598; (h) J. Wei and Z. Sun, Org. Lett., 2015, 17, 5396; (i) M. J. Barrett, G. F. Khan, P. W. Davies and R. S. Grainger, Chem. Commun., 2017, 53, 5733; $(j)$ B. Alcaide, P. Almendros and C. Lázaro-Milla, Adv. Synth. Catal., 2017, 359, 2630.

17 A. K. Yadav, B. K. Singh, N. Singh and R. P. Tripathi, Tetrahedron Lett., 2007, 48, 6628.

18 G.-Y. J. Im, S. M. Bronner, A. E. Goetz, R. S. Paton, P. H.-Y. Cheong, K. N. Houk and N. K. Garg, J. Am. Chem. Soc., 2010, 132, 17933; and references therein.

19 For selected reviews of arynes, see: (a) S. Yoshida and T. Hosoya, Chem. Lett., 2015, 44, 1450; (b) J. Shi, Y. Li and Y. Li, Chem. Soc. Rev., 2017, 46, 1707; (c) F. I. M. Idiris and C. R. Jones, Org. Biomol. Chem., 2017, 15, 9044; (d) H. Takikawa, A. Nishii, T. Sakai and K. Suzuki, Chem. Soc. Rev., 2018, 47, 8030; (e) T. Roy and A. T. Biju, Chem. Commun., 2018, 54, 2580. 